\title{
Los derechos políticos para las mujeres latinoamericanas son derechos humanos
}

\author{
The Political Rights for Latin American Women are Human \\ Rights
}

Teresa Cristina de Novaes Marques

Universidade de Brasília, Brasil

http://orcid.org/0000-0002-8452-6725

tcnmarques@unb.br

El 2 de mayo de 1948, después de que las protestas fueron barridas de las calles de Bogotá bajo fuerte represión de la policía, los representantes de dieciséis de los veintiún Estados afiliados en la Unión Panamericana se manifestaron acerca de la propuesta de dos convenciones que beneficiaban a las mujeres de América, una de ellas sobre derechos políticos y la otra sobre derechos civiles.

Entonces había gran expectativa con respecto a la Novena Conferencia Internacional Americana, cuyo propósito principal era establecer un nuevo sistema político para la región, con la creación de una entidad regional de espíritu renovado. Aunque fuera un aspecto lateral de la agenda de debates de la conferencia, las dos convenciones sobre los derechos de las mujeres eran parte de un debate sobre la estandarización de las instituciones políticas de los Estados americanos iniciado tres años antes. Originalmente, la materia fue considerada parte de la reformulación del sistema de defensa del continente, como informaba la prensa brasileña en febrero de 1946. En esta ocasión, la prensa reprodujo integralmente el discurso de toma de posesión del cargo de ministro de Relaciones 
Exteriores, por João Neves da Fontoura. El contenido de su discurso enfatizaba la importancia de promover la estandarización de las instituciones políticas en la región (Neves da Fontoura 2). Finalmente, se decidió tratar la cuestión de los derechos de las mujeres bajo la fórmula jurídica de convenciones.

El preámbulo de la Convención Interamericana sobre Concesión de los Derechos Políticos a la Mujer invoca las decisiones tomadas en la Conferencia de Chapultepec, realizada en febrero de 1945, para afirmar, por razones de justicia, que "La Mujer tiene derecho a igual tratamiento político que el hombre" ("Convención” 1).

Catorce países firmaron la convención en Bogotá, aunque muchos demoraron en ratificarla, después de someterla a probación por los poderes legislativos nacionales. El gobierno de Guatemala la firmó bajo reservas y el gobierno de México se abstuvo porque el documento entraba en conflicto con preceptos de su Constitución. Lo importante es que las dos convenciones de Bogotá ofrecieron un nuevo instrumento a la Comisión Interamericana de Mujeres, con el fin de presionar a los gobiernos para cambiar sus instituciones políticas y extender finalmente el derecho de sufragio a la población femenina adulta y escolarizada en la región. Uno después de otro, en los diez años siguientes, los países que aún no habían autorizado el voto de las mujeres, como México, Perú, Colombia y Paraguay, promovieron las reformas legales necesarias para adherir a las convenciones de 1948.

Esta nota tiene el propósito de discutir aspectos de los bastidores de la decisión de Bogotá, como quiénes participaron de su elaboración, qué objetivos pretendían y cómo la materia llegó al formato jurídico de convenciones. Este es un capítulo importante de la política interamericana de la posguerra, que no se discute habitualmente. Una historia que involucra a Brasil, Chile y México, entre otros países cuyos diplomáticos participaron de los debates en torno a la definición de los derechos y deberes fundamentales del hombre, lo que asumió el formato de la Declaración Americana de los Derechos y Deberes del Hombre, también firmada en Bogotá.

El objetivo de este ejercicio no es volver menos relevante el esfuerzo que mujeres de todos los espectros políticos hicieron en las Américas para conquistar el derecho de sufragio. Por el contrario, esta nota releva un aspecto poco conocido de la política interamericana para indagar 
por qué razones los derechos de las mujeres se propusieron como parte de las negociaciones diplomáticas en la región durante la posguerra.

¿Por qué el derecho de sufragio, por tantas décadas demandado por las mujeres latinoamericanas, fue establecido como un compromiso entre Estados soberanos en este momento político de las Américas? La respuesta a esa importante cuestión depende de los esfuerzos de investigadores de más de un país. Cada uno de los gobiernos que participaron del concierto sobre las reformas institucionales necesarias en la región tenía su propia motivación política. Pero el primer paso para esclarecer este aspecto de la política regional en la posguerra puede ser examinar el documento original, preparado por el Comité Jurídico Interamericano y divulgado en diciembre de 1945, que incluyó el derecho de sufragio de hombres y de mujeres entre los derechos humanos que los países deberían respetar.

Este documento corresponde a un dossier de 80 páginas que se encuentra en los archivos del Ministerio de Relaciones Exteriores de Brasil, en Brasilia. El texto fue elaborado por el mencionado comité, en ese momento bajo la presidencia del jurista brasileño Francisco Campos (1891-1968), con la colaboración del diplomático chileno Félix Nieto Del Río, el norteamericano Charles Fenwick y el diplomático mexicano Antonio Gómez Robledo. Así, el comité definió cuáles eran los derechos fundamentales del hombre americano:

I Derecho a la vida

II Derecho a la libertad personal

III Derecho a la libertad de palabra y de expresión

IV Derecho a la libertad de religión y de culto

V Derecho a la libertad de reunión

VI Derecho a la libertad de asociación

VII Derecho de peticionar

VIII Derecho a la propiedad

IX Derecho a la nacionalidad

$\mathrm{X}$ Derecho de libertad de tener relaciones de familia

XI Derecho de protección contra aprisionamiento arbitrario 
XII Derecho de tener proceso y juzgamiento adecuados

XIII Derecho de tomar parte en elecciones

XIV Derecho al trabajo

XV Derecho de participar de los beneficios de la ciencia

XVI Derecho a la seguridad económica

XVII Derecho a la educación

XVIII Derecho a la igualdad ante la ley

XIX Derecho y deberes correlativos

XX Derecho de incorporar la declaración en las leyes nacionales

XXI Derecho a proceso en casos relativos a extranjeros (MRE-Brasília; 42.804).

El espíritu que animó a los miembros del comité fue el de construir un conjunto de principios fundamentales de derecho internacional que los países signatarios de la Declaración Americana de los Derechos y Deberes del Hombre aceptarían respetar. Entre esos derechos estaba el de votar. El comité justificó incluir el sufragio entre los derechos fundamentales del hombre porque la experiencia reciente de los gobiernos totalitarios había privado a sus pueblos de los derechos fundamentales de libertad de expresión, lo que constituyó una amenaza a la paz del mundo. Además, la Resolución VII de la Conferencia de Chapultepec temía que la propaganda de doctrinas totalitarias en el continente representase un peligro para la tradición democrática en las Américas, por lo que cabía tomar medidas para contener una posible influencia subversiva.

Por eso, el artículo XIII del esbozo elaborado por el comité en 1945 estipulaba que todo individuo debía tener derecho a participar de elecciones en todos los niveles de gobierno, sin restricciones de raza, credo o sexo. La cualificación para votar, sin embargo, debería seguir la política interna de cada país, aunque el comité recomendase que los electores debiesen mostrarse aptos a comprender los principios de la vida política, lo que señalaba que el criterio de educación debería ser adoptado por los países cuando hiciesen sus reformas legales. Dadas las altas tasas de analfabetismo en las Américas por ese entonces, uno puede comprender el efecto excluyente de esa recomendación. 
Para hacer públicos los trabajos del comité, su presidente, Francisco Campos, hizo publicar en un periódico jurídico el resultado de los debates que los juristas tuvieran en 1945, provocados por las decisiones de la Conferencia de Chapultepec, realizada en febrero del mismo año (Campos, "O esboço" 5-10).

Los principios filosóficos liberales que ofrecen el fundamento para el documento preparado por el comité contrastan con la trayectoria de Francisco Campos como hombre de gobierno de Getúlio Vargas (1930-1945), que gobernó Brasil como dictador desde noviembre de 1937 hasta octubre de 1945, cuando fue depuesto. Campos sirvió al gobierno Vargas de muchas maneras e incluso redactó la Constitución autoritaria de 1937, que ofreció plenos poderes al jefe de Estado. Para justificar la ruptura con lo que restaba de democracia en el país en 1937, Campos escribió que el liberalismo político y económico conducían al comunismo (cit. en Medeiros 89). Para los que conocían sus preferencias políticas de juventud, el posicionamiento autoritario de Campos no era una sorpresa. En 1921, ya se había declarado contrario a la idea de libertad como un derecho natural y favorable a la centralización política en el Estado (Medeiros 72).

Sin embargo, los biógrafos de Campos no han ofrecido suficiente importancia a su nominación para presidir el Comité Jurídico Interamericano en 1942. Este fue el momento en que Brasil se encontró más próximo a los Estados Unidos, al punto de comprometerse en la Segunda Guerra Mundial y declarar la guerra al Eje. Para uno de los más reconocidos analistas de la vida política y jurídica de Campos, su nombramiento para el órgano de la Unión Panamericana marcó su gradual distanciamiento del gobierno de Vargas (Medeiros 99). Pero, aunque Campos se hubiese transformado en un crítico del presidente brasileño por no promover el retorno a la democracia a inicios de 1945 , quedó al frente del comité hasta 1954, fortaleciendo el posicionamiento diplomático de Brasil en el escenario interamericano. Esos años fueron decisivos para consolidar la diplomacia regional de combate al nazismo y al comunismo. Campos, que jamás dejo de rechazar el comunismo, encontró en el comité otros caminos para combatir lo que el documento señala como la propagación de ideologías totalitarias en el continente.

Al examinar la prensa brasileña posterior a la caída de Vargas, como también otras declaraciones de autoridades políticas de Brasil, se constata 
que el comité ocupaba un lugar importante en la política exterior del país. Creado en su formato original en 1906, el comité fue presidido por un jurista de Brasil desde 1912 hasta 1967 y una vez más entre 1969 y 1973, demostrando su importancia en el proyecto diplomático brasileño para la región (Ribeiro 98).

La importancia del trabajo del comité fue admitida por el representante de Chile en el órgano, Félix Nieto del Río. En la ocasión del anuncio del esbozo de declaración, Del Río habló con un influyente periódico de Río de Janeiro y destacó que la propuesta ofrecía protección internacional a los derechos esenciales del hombre, desde el momento en que los Estados del continente la aceptasen ("Direitos e deveres" 2). El diplomático chileno añadió que pensaba que el sufragio era la mejor arma democrática del pueblo, siempre que los ciudadanos lo ejerciesen según doctrinas de carácter democrático.

Finalmente, la obra de reformulación del sistema interamericano llevó al Tratado de Defensa Continental, firmado en Río de Janeiro en 1947, que incluiría más tarde las convenciones de derechos y la Declaración Americana de los Derechos y Deberes del Hombre firmadas en Bogotá, en 1948. Vale mencionar que entre las decisiones acordadas por los representantes de los Estados presentes en Bogotá estaba el derecho de sufragio en iguales condiciones para hombres y mujeres.

El documento preparado por el Comité Jurídico Interamericano eligió los derechos que debían ser consagrados como fundamentales a los individuos en las Américas. Resta mucho por conocer acerca de las expectativas políticas de cada uno de los países involucrados en la obra de construcción del sistema interamericano en la posguerra, así como las razones para elegir los derechos mencionados como derechos humanos, incluso con anterioridad a la conocida Declaración Universal de los Derechos Humanos de las Naciones Unidas, proclamada en diciembre de 1948.

Mi propósito en este breve comentario ha sido llamar la atención de los investigadores e investigadoras de Latinoamérica sobre la importancia de los debates promovidos por el Comité Jurídico Interamericano, con el objetivo de animarlos a realizar investigaciones en cada uno de sus países. De esa forma, en un futuro, quizá podamos comprender mejor el rol de la diplomacia interamericana en las reformas institucionales promovidas para la conquista de derechos políticos en la región. 


\section{BibliografíA}

Comissão Jurídica Interamericana. Esboço de Declaração dos Direitos e Deveres Internacional do Homem, 31 de diciembre de 1945. (Esbozo de Declaración de los Derechos y Deberes del Hombre), Archivo del Ministerio de Relaciones Exteriores - Brasília, carpeta 42.804.

Campos, Francisco. "Esboço de Declaração dos Direitos e Deveres Internacionais do Homem". Revista Forense, 1946, pp. 5-10. 1941. . O Estado Nacional. Río de Janeiro, José Olympio Editora,

"Convención Interamericana sobre Concesión de los Derechos Políticos a la Mujer". Oas.org. Organización de los Estados Americanos. Web. Disponible en: https://www.oas.org/dil/esp/convencion_interamericana_sobre_concesion_derechos_politicos_a_la_mujer.pdf

"Direitos e deveres internacionais do Homem" (Derechos y deberes internacionales del Hombre). Jornal do Comércio, 12 de febrero de 1946, p. 2.

Medeiros, Jarbas. "Introdução ao estudo do pensamento político autoritário brasileiro, 1914/1945, Francisco Campos”. Revista de Ciência Política, vol. 17, Nº1, pp. 59-102.

Neves da Fontoura, JoÃo. "O papel do Brasil na elaboração da paz" (El rol de Brasil en la elaboración de la paz). A Noite, 2 de febrero de 1946, p. 2.

Ribeiro, Renato. "Breve história da Comissão Jurídica Interamericana e de sua obra”. Revista de Ciência Política, vol. 33, N², 1990, pp. 85-99. 